\title{
Effects of Content of Chopped Glass Fibers on the Properties of Silica Filled PTFE Composites
}

\author{
Ying Yuan ${ }^{1,2}$, Haodong Lin ${ }^{1,2}$, Zehua Jiang1,2, Zhifeng Chi1,2, Minghao Yao, ${ }^{1,2}$, Shuren Zhang ${ }^{1,2}$ \\ ${ }^{1}$ National Engineering Center of Electromagnetic Radiation Control Materials, University of Electronic Science and Technology of \\ China, Chengdu, China \\ ${ }^{2}$ State Key Laboratory of Electronic Thin Films and Integrated Devices, University of Electronic Science and Technology of China, \\ Chengdu, China \\ Email: *yingyuan@uestc.edu.cn
}

How to cite this paper: Yuan, Y., Lin, H.D., Jiang, Z.H., Chi, Z.F., Yao, M.H. and Zhang, S.R. (2017) Effects of Content of Chopped Glass Fibers on the Properties of Silica Filled PTFE Composites. Journal of Materials Science and Chemical Engineering, 5, 36-44.

https://doi.org/10.4236/msce.2017.57005

Received: April 10, 2017

Accepted: July 4, 2017

Published: July 7, 2017

\begin{abstract}
In this work, the polytetrafluoroethylene (PTFE)-based composite substrates were manufactured by mixing, calendering, hot-pressing sintering. The composition of all the samples was $\mathrm{PTFE}, \mathrm{SiO}_{2}$ and chopped E-glass fibers. The effects of content of E-glass fibers on the properties of the $\mathrm{SiO}_{2}$ filled PTFE composites were investigated, including density, water absorption, dielectric properties $\left(\varepsilon_{\mathrm{r}}, \tan \delta\right)$, coefficient of thermal expansion (CTE) and temperature coefficient of dielectric constant $\left(\tau_{\varepsilon}\right)$. The compositions of inorganic materials mixture are $(62-\mathrm{x}) \% \mathrm{SiO}_{2}+\mathrm{x} \%$ E-glass fiber ( $\mathrm{x}$ : mass ratio to composites, $\mathrm{x}$ $=0,1,1.5,2,2.5,3)$. The results show that as the content of E-glass fibers is $2.5 \mathrm{wt} . \%$, this composite obtains optimal properties, including excellent dielectric properties $\left(\mathcal{E}_{\mathrm{r}} \sim 2.9123, \tan \delta \sim 0.0011\right)$, acceptable water absorption of $0.075 \%$, temperature coefficient of dielectric constant of $10 \mathrm{ppm} /{ }^{\circ} \mathrm{C}$ and coefficient of thermal expansion of $15.87 \mathrm{ppm} /{ }^{\circ} \mathrm{C}$.
\end{abstract}

\section{Keywords}

Polymers, Composite Materials, PTFE, Dielectric Properties, E-Glass Fiber

\section{Introduction}

Microwave composite substrate materials play a key role in global society with a wide range of applications from terrestrial and satellite communication including software radio, GPS, and DBS TV to environmental monitoring via satellites. PTFE polymer has been widely studied as high-frequency microwave substrates material because of its ideal microwave dielectric properties, temperature and chemical resistance [1] [2]. However, PTFE has some disadvantages, such as high linear coefficient of thermal expansion $\left(\mathrm{CTE} 109 \mathrm{ppm} /{ }^{\circ} \mathrm{C}\right)$ and poor for- 
mability [2]. In order to solve these problems, many researchers have tried to reduce its high CTE and improve the formability by adding inorganic materials into PTFE matrix, such as silica $\left(\mathrm{SiO}_{2}\right)$ [3] [4], alumina $\left(\mathrm{Al}_{2} \mathrm{O}_{3}\right)$ [5], magnesium titanate $\left(\mathrm{MgTiO}_{3}\right)$ [6], $\mathrm{TiO}_{2}$ [7], $\mathrm{CaTiO}_{3}$ [8], and so on. Among above composites, the PTFE $/ \mathrm{SiO}_{2}$ composites have low dielectric constant, dielectric loss and low CTE. It has been reported that $60 \mathrm{wt} . \%$ untreated $\mathrm{SiO}_{2}$ filled PTFE composite has a dielectric constant of 2.9, dielectric loss of 0.0024 and CTE of 45 $\mathrm{ppm} /{ }^{\circ} \mathrm{C}$ [3] [4]. Chopped E-glass fiber is incorporated in the PTFE matrix to control surface texture and to enhance mechanical properties. Experiments on ceramic filled PTFE composites ( $\mathrm{PTFE} / \mathrm{Al}_{2} \mathrm{O}_{3}, \mathrm{PTFE} / \mathrm{SrTiO}_{3}$ and $\mathrm{PTFE} / \mathrm{CaTiO}{ }_{3}$ ) show that 2 wt.\% E-glass chopped fiber in PTFE matrix exhibit desirable mechanical and surface properties [9]. It is well known that copper conductor layer is laminated over PTFE substrate for circuit fabrication. Therefore, the CTE of composite is a key parameter for microwave substrate, which should be close to that of copper $\left(\mathrm{CTE} \sim 17 \mathrm{ppm} /{ }^{\circ} \mathrm{C}\right)$ [10]. As is well know, E-glass fiber has a CTE of approximately $4.8 \mathrm{ppm} /{ }^{\circ} \mathrm{C}$, which is far less than that of PTFE about 109 $\mathrm{ppm} /{ }^{\circ} \mathrm{C}$. In this work, the effects of content of chopped E-glass fibers on the properties of the $\mathrm{SiO}_{2}$ filled PTFE composites were investigated, including density, water absorption, dielectric properties, coefficient of thermal expansion and temperature coefficient of dielectric constant.

\section{Experimental Procedures}

The raw materials used in this study were PTFE suspension (TE-3865C, DuPont, China), E-glass fiber (Nanjing Glass Fiber Research and Design Institute, china) and fused amorphous $\mathrm{SiO}_{2}$ powder ( $\geq 99.5 \%$, Huawei Powder Technology Co, Ltd, China) with an average size of $8.3 \mu \mathrm{m}$. The performances of raw materials are shown in Table 1. Surface of glass fiber and silica are treated with silane coupling agents. $\mathrm{SiO}_{2}$ powders, short E-glass fibers and PTFE aqueous dispersion were weighed accurately and mixed by high speed dispersing machine for $1 \mathrm{~h}$ to prepare the composites. The obtained slurry was then filtered at $25^{\circ} \mathrm{C}$ to remove water. Afterwards, the dough is pressed into a sheet by a calender. Then, the obtained sheet was hot pressed and sintered into a rectangular shape at $20 \mathrm{MPa}$ in $370^{\circ} \mathrm{C}$ in a program controlled furnace for $2 \mathrm{~h}$, and then cooled with furnace.

\section{Characterization Studies}

Scanning electron microscopy (SEM, model JEOL JSM-6490) was used to observe the morphology of E-glass fibers and microstructure of the composites.

Table 1. Properties of PTFE, $\mathrm{SiO}_{2}$ and E-glass fiber.

\begin{tabular}{ccccc}
\hline & $\begin{array}{c}\text { Dielectric constant } \\
\left(\varepsilon_{\mathrm{r}}\right)\end{array}$ & $\begin{array}{c}\text { Dielectric loss } \\
\tan \delta\end{array}$ & $\begin{array}{c}\text { Density/ } \\
(\mathrm{g} / \mathrm{cm} 3)\end{array}$ & $\begin{array}{c}\text { Coefficient of thermal } \\
\text { expansion }(\mathrm{CTE}) /\left(\mathrm{ppm} /{ }^{\circ} \mathrm{C}\right)\end{array}$ \\
\hline $\mathrm{PTFE}$ & 2.1 & 0.0003 & 2.2 & 109 \\
$\mathrm{SiO}_{2}$ & 3.83 & 0.0025 & 2.3 & 0.5 \\
E-glass fiber & 6.11 & 0.006 & 2.53 & 4.8 \\
\hline
\end{tabular}


The coefficients of thermal expansion of the composites were measured by TMA 2940 according to IPC-TM-650 2.4.41 [11]. The densities of the composites were measured by the Archimedes method. Moisture absorption of the composites was figured out as reported earlier by Murali etc. according to IPC-TM-650 2.6.2 [11]. The dielectric constant, dielectric loss and temperature coefficient of dielectric constant of the composites were measured by Agilent E8363A microwave network analyzer using stripline resonator method according to IPC-TM650 2.5.5.5 specification [12]. The testing frequencies covered the region from 7.0 GHz to $13.0 \mathrm{GHz}$. In this article, $\mathcal{E}_{\mathrm{r}}$ and $\tan \delta$ of the composites reported was at a frequency around $10 \mathrm{GHz}$.

\section{Results and Discussion}

Figure 1 shows the SEM micrographs of the non-treated E-glass fibers and treated E-glass fibers. It could be observed that E-glass fibers become smoother and no agglomerate after being treated by silane coupling agent. Figure 2 shows the brittle fractured cross sectional SEM micrographs of composites with different contents of E-glass fiber. In this work, as the glass fiber content is relatively small, it is difficult to find fiberglass by SEM, further indicating that the glass fibers are evenly distributed in the composite materials.

The variation in experimental and theoretical density with different contents of E-glass fiber in the composites is shown in Figure 3(a). The theoretical density of the composites $\rho_{c}$ is calculated using the rule of mixtures (Equation (1)) [6].

$$
\rho_{c}=\rho_{f} V_{f}+\rho_{m} V_{m}
$$

where $\rho_{\mathrm{f}}$ and $\rho_{\mathrm{m}}$ are the densities and $\mathrm{V}_{\mathrm{f}}$ and $\mathrm{V}_{\mathrm{m}}$ are the volume fractions of filler and matrix, respectively. From Figure 3(a), it is obvious that the experimental density increases with E-glass fiber loading up to 2 wt.\% and then keep unchanged with E-glass fiber loading up to 3 wt.\%. This result is due to the density of the glass fiber is greater than that of silica. So the density of composites increases with an increase of content of E-glass fiber. It can be seen that the experimental density increases slightly with the loading of the filler. The difference between the experimental density and the theoretical density is due to the higher
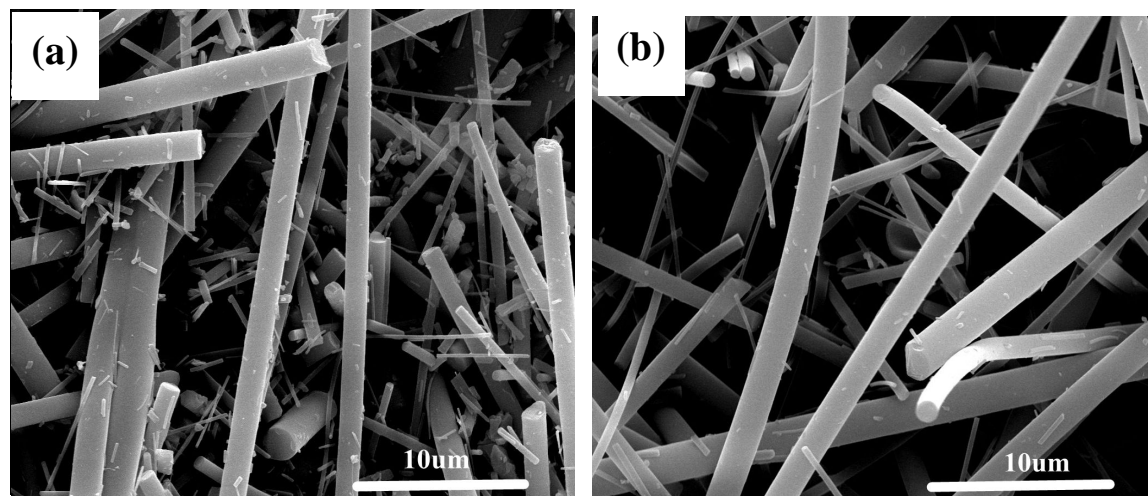

Figure 1. SEM micrographs of (a) non-treated fused E-glass fiber (b) treated E-glass fiber. 

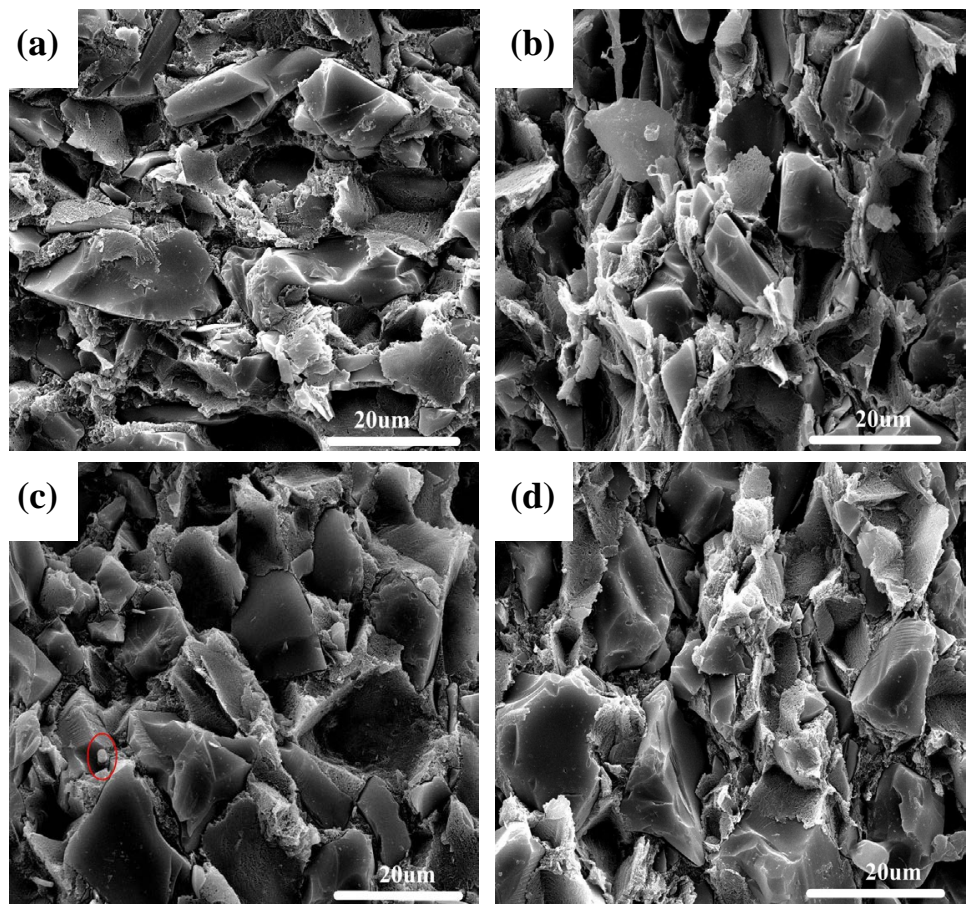

Figure 2. Brittle fractured cross sectional SEM micrographs of composite at different contents of E-glass fiber (a) 0 wt.\%; (b) 1.5 wt.\%; (c) 2.5 wt.\%; (d) 3 wt.\%.
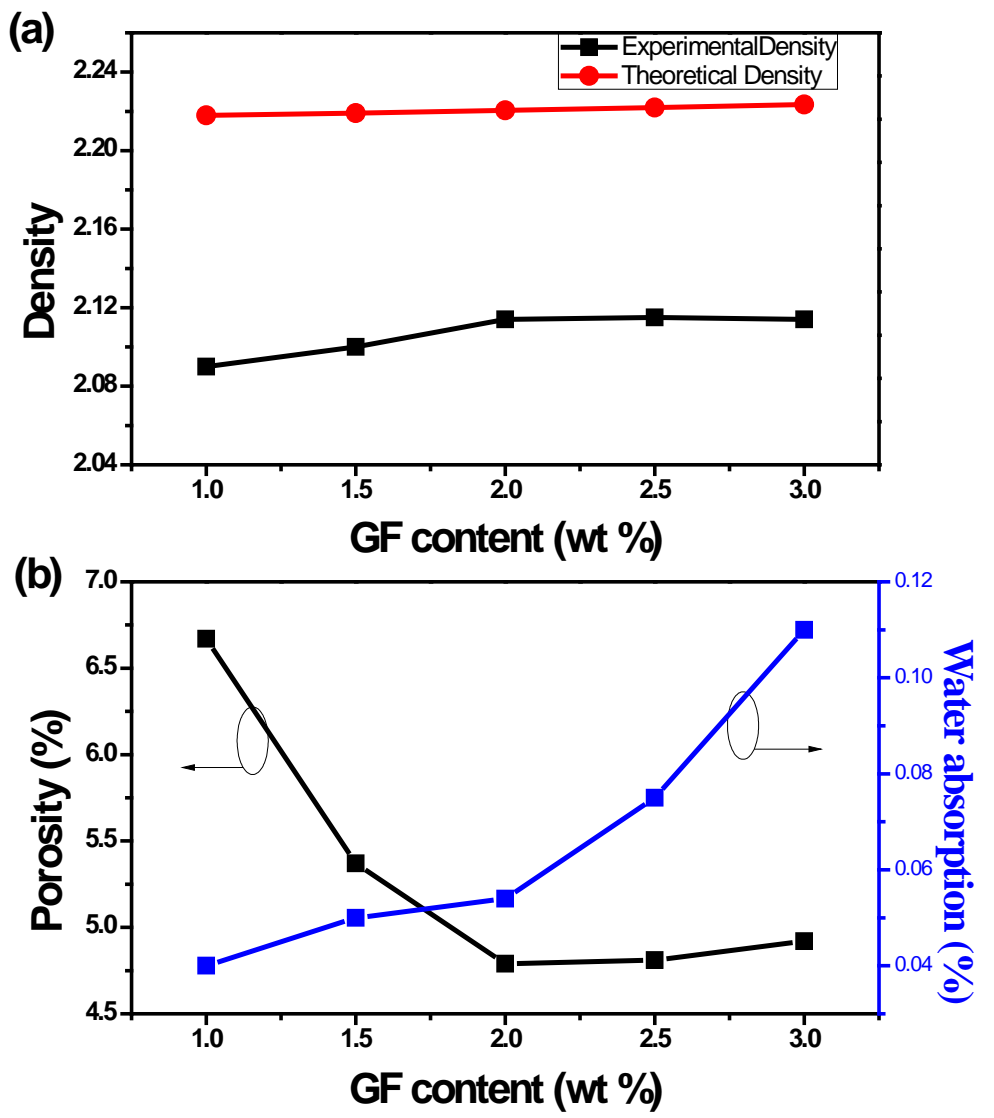

Figure 3. (a) The variation in experimental density and theoretical density with respect to E-glass fiber loading; (b) The variation in porosity and water absorption with respect to E-glass fiber loading. 
packing load. The formation of pores in the composite material may be the main reason for this deviation, which is not considered in the theoretical calculation. The variation in porosity and water absorption with different contents of E-glass fiber in the composites is shown in Figure 3(b). It can be seen that porosity decreases with E-glass fiber loading up to $2 \mathrm{wt} . \%$ and then slowly increases with E-glass fiber loading up to $3 \mathrm{wt} . \%$. However, water absorption of the composites increases with different contents of E-glass fiber. This is maybe attributed to the fact that the capillary action of the E-glass fibers causes the water to spread along the interface.

Variation of dielectric constant and dielectric loss with respect to weight fraction of E-glass fiber in the PTFE matrix is shown in Figure 4. Dielectric constant increases with E-glass fiber loading up to $3 \mathrm{wt} . \%$. Dielectric loss increases with E-glass fiber loading up to $1.5 \mathrm{wt} . \%$ and then decreases with E-glass fiber loading up to $2.5 \mathrm{wt}$ \%. Then dielectric loss increases with E-glass fiber loading up to 3 wt.\%. This result is due to the dielectric constant of the glass fiber is greater than the dielectric constant of the silica. At the same time, density increases with E-glass fiber loading as shown in Figure 3. Thus, the number of polarized particles increases in per unit volume and $\mathcal{E}_{\mathrm{r}}$ of the composites increases. Furthermore, when the composite has fewer pore, the air content decreases, resulting in a decrease of dielectric loss. At the same time, the dielectric loss of E-glass fiber is higher than that of silica and PTFE. So a minimum dielectric loss is obtained with 2.5 wt.\% content of E-glass fiber.

The variation of CTE at different directions $(\mathrm{X} / \mathrm{Y} / \mathrm{Z})$ is shown in Figure 5. The value of CTE at $Z$ direction increases firstly with $1.5 \mathrm{wt} . \%$ content of E-glass fiber, and then decreases up to $2.5 \mathrm{wt} . \%$ content of E-glass fiber, and then shows a little increase at $3.0 \mathrm{wt} . \%$ fiber. However, the thermal expansion changes at $\mathrm{X}$ and $\mathrm{Y}$ directions are not significant. A minimum CTE of composites is obtained when content of E-glass fiber is $2.5 \mathrm{wt} . \%$. E-glass fiber is tightly connected with PTFE and embedded in PTFE homogeneously. E-glass fiber could restrain the

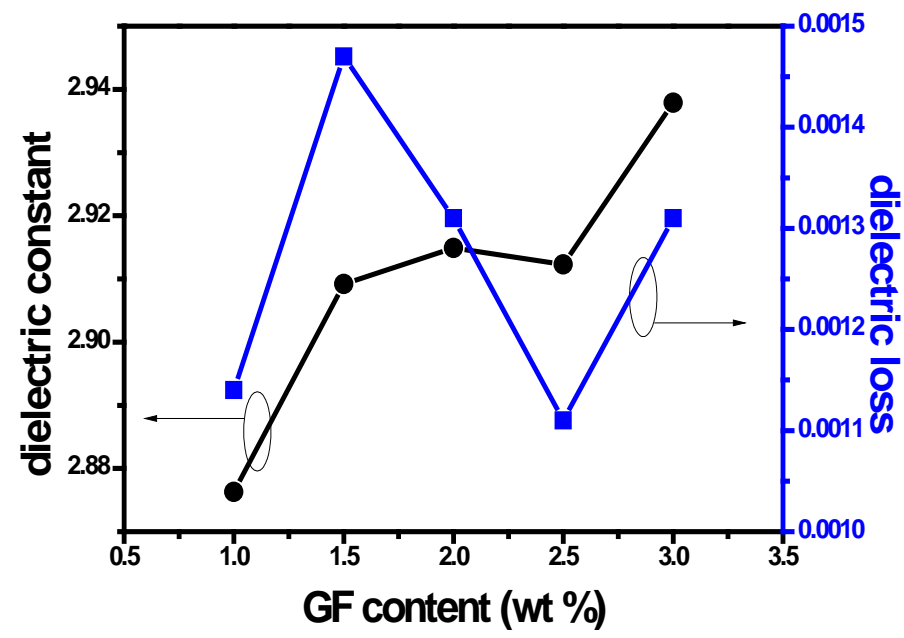

Figure 4. The variation of dielectric constant and dielectric loss at $10 \mathrm{GHz}$ of $\mathrm{PTFE} / \mathrm{SiO}_{2}$ composites with respect to E-glass fiber loading. 


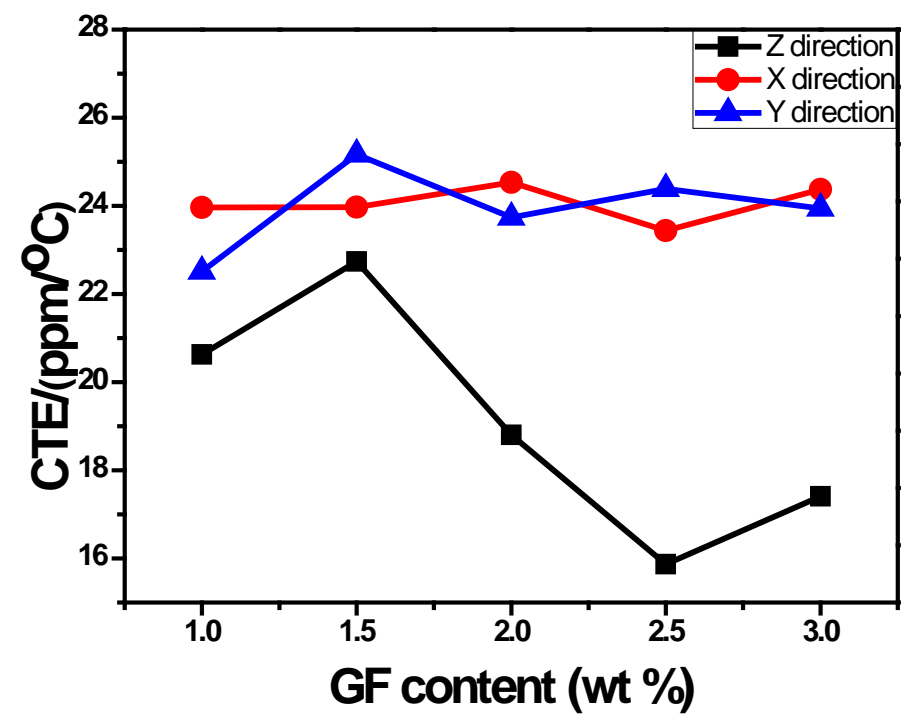

Figure 5. The variation of CTE with respect to E-glass fiber loading.

thermal expansion of PTFE polymer when temperature is increased. The randomly distributed mixture of PTFE and E-glass fibers is initially compression moulded. The E-glass fibers tend to align perpendicular to the direction of compression during pressing [13]. Since the ceramic filling amount is high, the glass fiber is substantially inclined in the substrate. Therefore, the thermal expansion coefficient has more obvious change in the $\mathrm{Z}$ direction. The calendering process leaves air entrapped in the structure. In the form of small micro air bubbles are possibly entrapped between the E-glass fibers. When heated, the air tends to expand much more than the polymers and glass fibers, forcing the glass fibers to expand more in $\mathrm{X}$ and $\mathrm{Y}$ direction [13]. Therefore, the thermal expansion coefficient in the $\mathrm{X}$ and $\mathrm{Y}$ direction are larger than the thermal expansion coefficient in the $\mathrm{Z}$ direction.

The dielectric constant temperature coefficient has a similar trend with CTE. In this work, the $\tau_{\varepsilon}$ of composites is studied within the temperature range from $0^{\circ} \mathrm{C}$ to $100^{\circ} \mathrm{C}$. The $\tau_{\varepsilon}$ values of the composites are calculated using Equation 2 [14].

$$
\tau_{\varepsilon}=\frac{1}{\varepsilon_{\gamma}} \times \frac{\Delta \varepsilon_{\gamma}}{\Delta \mathrm{T}}
$$

where $\varepsilon_{r}$ is the dielectric constant at $25^{\circ} \mathrm{C}$ and $\frac{\Delta \varepsilon_{r}}{\Delta T}$ is the change of dielectric constant with respect to temperature. The variation of $\tau_{\varepsilon}$ with respect to E-glass fiber loading is shown in Figure 6. The most important factors that control the temperature coefficient of dielectric constant are the change in the polarization of the material with respect to its temperature and its linear coefficient of thermal expansion (Equation (3)) [14]:

$$
\tau_{\varepsilon}=\frac{\varepsilon_{\gamma}^{\prime}}{3}\left(\frac{1}{\alpha} \times \frac{\partial \alpha}{\partial T}-3 \alpha_{L}\right)
$$

where the first term represents the change in polarization of the system, and the 


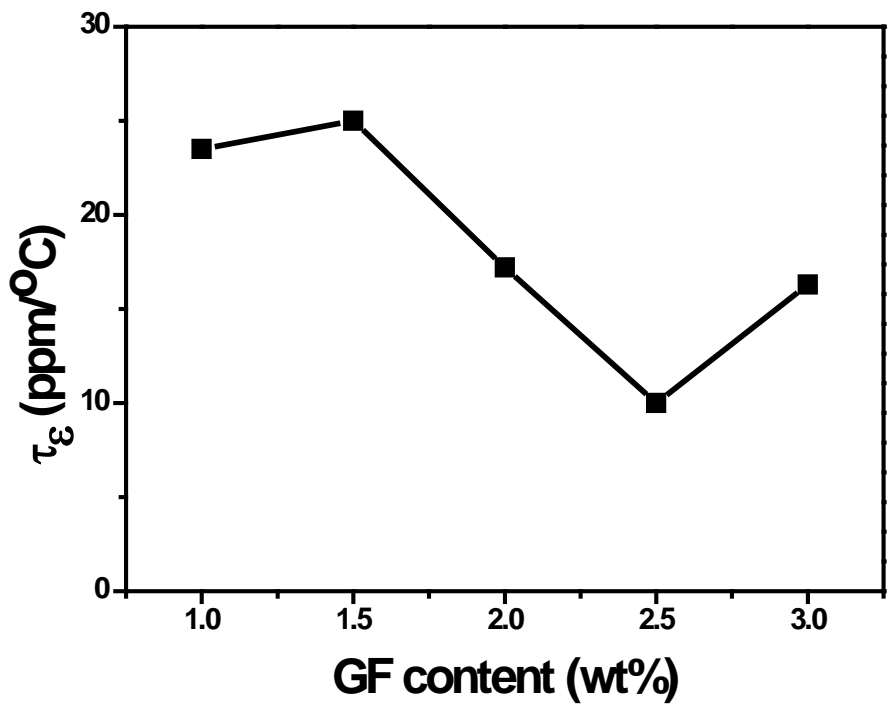

Figure 6. The variation of $\tau_{\varepsilon}$ with respect to E-glass fiber loading.

second term represents the linear coefficient of thermal expansion. In this composite system, PTFE molecules don't have polarity due to its symmetric structure. Therefore, the polarization type of PTFE is only electronic displacement polarization so that PTFE shows a negative $\tau_{\varepsilon}$ of $-400 \mathrm{ppm} /{ }^{\circ} \mathrm{C}$ [10]. On the contrary, $\mathrm{SiO}_{2}$ ceramic and E-glass fibers present a positive $\tau_{\varepsilon}$ resulted from its dominant ionic displacement polarization. In this work, $\tau_{\varepsilon}$ is dominantly controlled by the polarization variation of PTFE polymer, E-glass fibers and $\mathrm{SiO}_{2}$ ceramic with respect to temperature, and the linear coefficient of thermal expansion of composites.

\section{Conclusion}

In this work, the effects of glass fiber content on the properties of the composites were investigated, such as dielectric properties, density, water absorption, coefficient of thermal expansion, and dielectric constant temperature coefficients. The microstructure of the composites was observed by scanning electron microscopy, which further proved the effect of the glass fibers in the composites. The optimum dielectric properties and the dielectric constant temperature coefficient values were obtained when the glass fiber content was $2.5 \%$. E-glass fiber could restrain the thermal expansion of PTFE polymer when temperature is increased. The smaller thermal expansion coefficient values were obtained.

\section{References}

[1] Murali, K.P., Rajesh, S., Prakash, O.M., Kulkarni, A.R. and Ratheesh, R. (2009) Key Words: Polymers, Composite Materials, PTFE, Dielectric Properties, Compound Coupling Agents. Composites Part A: Applied Science and Manufacturing, 40, 1179-1185.

http://www.sciencedirect.com/science/article/pii/S1359835X09001377 https://doi.org/10.1016/j.compositesa.2009.05.007

[2] Pan, C., Kou, K.C., Jia, Q., Zhang, Y., Wu, G.L. and Ji, T.Z. (2016) Improved Ther- 
mal Conductivity and Dielectric Properties of hBN/PTFE Composites via Surface Treatment by Silane Coupling agent. Composites Part B: Engineering. http://www.sciencedirect.com/science/article/pii/S1359836816319035

[3] Chen, Y.C., Lin, H.C. and Lee, Y.D. (2003) The Effects of Filler Content and Size on the Properties of PTFE/SiO2 Composites. Journal of Polymer Research, 10, 247-258. https://doi.org/10.1023/B:JPOL.0000004620.71900.16

[4] Chen, Y.C., Lin, H.C. and Lee, Y.D. (2004) The Effects of Phenyltrimethoxysilane Coupling Agents on the Properties of PTFE/Silica Composites. Journal of Polymer Research, 11, 1-7. https://doi.org/10.1023/B:JPOL.0000021757.94577.a3

[5] Murali, K.P., Rajesh, S., Nijesh, K.J. and Ratheesh, R. (2010) Effect of Particle Size on the Microwave Dielectric Properties of Alumina-Filled PTFE Substrates. International Journal of Applied Ceramic Technology, 7, 475-481. https://doi.org/10.1111/j.1744-7402.2009.02483.x

[6] Yuan, Y., Zhang, S.R., Zhou, X.H. and Li, E.Z. (2013) $\mathrm{MgTiO}_{3}$ Filled PTFE Composites for Microwave Substrate Applications. Materials Chemistry and Physics, 141, 175-179. https://doi.org/10.1016/j.matchemphys.2013.04.043

[7] Rajesh, S., Nisa, V.S., Murali, K.P. and Ratheesh, R. (2009) Microwave Dielectric Properties of PTFE/Rutile Nanocomposites. Journal of Alloys and Compounds, 477, 677-682.

http://www.sciencedirect.com/science/article/pii/S0925838808017787 https://doi.org/10.1016/j.jallcom.2008.10.092

[8] Rajesh, S., Murali, K.P. and Ratheesh, R. (2009) Preparation and Characterization of High Permittivity and Low Loss $\mathrm{PTFE} / \mathrm{CaTiO}_{3}$ Microwave Laminates. Polymer Composites, 30, 1480-1485.

http://onlinelibrary.wiley.com/doi/10.1002/pc.20716/full

https://doi.org/10.1002/pc.20716

[9] Murali, K.P., Rajesh, S., Prakash, O.M., Kulkarni, A.R. and Ratheesh, R. (2010) Effects of Silane Coatings in Aqueous and Non-Aqueous Media on the Properties of Magnesia Filled PTFE Laminates. Materials Chemistry and Physics, 122, 317-320. https://doi.org/10.1016/j.matchemphys.2010.03.014

[10] Yuan, Y., Yin, Y.T., Yu, D.D., Lin, H.D., Wang, J., Tang, B., et al. (2016) Effects of Compound Coupling Agents on the Properties of PTFE/SiO2 Microwave Composites. Journal of Materials Science: Materials in Electronics, 28, 3356-3363. https://doi.org/10.1007/s10854-016-5929-8

[11] Pathmanathan, K., Cavaille, J.Y. and Johari, G.P. (1988) Dielectric Relaxations of Microstructurally Different Latex Polymer Blends of Poly (Butyl Acrylate) and Poly (vinyl Acetate). Polymer, 29, 311-319.

http://xueshu.baidu.com/s?wd=paperuri\%3A\%283345bc24ad69b4f9228d60b97ba0f $\underline{6 \mathrm{db} \% 29 \& \text { filter }=\mathrm{sc} \text { long } \operatorname{sign} \& \mathrm{tn}=\mathrm{SE} \text { xueshusource } 2 \mathrm{kduw} 22 \mathrm{v} \& \mathrm{sc} \text { vurl=http } \% 3 \mathrm{~A}}$ \%2F\%2Fwww.sciencedirect.com\%2Fscience\%2Farticle\%2Fpii\%2F003238618890339 $\underline{4 \& i e=u t f-8 \& s c \text { us }=7490547394596071234}$ https://doi.org/10.1016/0032-3861(88)90339-4

[12] Yue, H., Virga, K.L. and Prince, J. (1998) Dielectric Constant and Loss Tangent Measurement Using a Stripline Fixture. IEEE Transactions on Components Packaging \& Manufacturing Technology Part B, 21, 1077-1082.

http://xueshu.baidu.com/s?wd=paperuri\%3A\%289263bea7b17d7764d39b4ffedc61c1 c3\%29\&filter=sc long sign\&tn=SE xueshusource $2 \mathrm{kduw} 22 \mathrm{v} \& \mathrm{sc}$ vurl=http $\% 3 \mathrm{~A} \%$ 2F\%2Fieeexplore.ieee.org\%2Fxpl\%2Ffreeabs all.jsp\%3Farnumber\%3D730427\&ie $=\mathrm{u}$ tf-8\&sc us $=5858350711289994897$ https://doi.org/10.1109/96.730430 
[13] Xi, Z., Ghita, O.R. and Evans, K.E. (2012) The Unusual Thermal Expansion Behaviour of PTFE/GF Composites Incorporating PTFE/GF Recyclate. Composites Part A: Applied Science and Manufacturing, 43, 1999-2006.

http://ac.els-cdn.com/S1359835X1200214X/1-s2.0-S1359835X1200214X-main.pdf? $\underline{\mathrm{tid}}=405 \mathrm{a} 64 \mathrm{e} 6-3 \mathrm{f} 34-11 \mathrm{e} 6-8 \mathrm{c} 22-00000 \mathrm{aab} 0 \mathrm{f} 01 \& \mathrm{acdnat}=1467340613 \mathrm{~d} 0 \mathrm{~b} 173 \mathrm{~b} 15 \mathrm{c} 3180$ 67f575bd0c9f6a5357

https://doi.org/10.1016/j.compositesa.2012.07.013

[14] Rajesh, S., Murali, K.P., Jantunen, H. and Ratheesh, R. (2011) The Effect of Filler on the Temperature Coefficient of the Relative Permittivity of PTFE/Ceramic Composites. Physica B: Condensed Matter, 406, 4312-4316.

https://doi.org/10.1016/j.physb.2011.08.080

Submit or recommend next manuscript to SCIRP and we will provide best service for you:

Accepting pre-submission inquiries through Email, Facebook, LinkedIn, Twitter, etc. A wide selection of journals (inclusive of 9 subjects, more than 200 journals)

Providing 24-hour high-quality service

User-friendly online submission system

Fair and swift peer-review system

Efficient typesetting and proofreading procedure

Display of the result of downloads and visits, as well as the number of cited articles

Maximum dissemination of your research work

Submit your manuscript at: http://papersubmission.scirp.org/

Or contact msce@scirp.org 